Pak. j. sci. ind. res. Ser. A: phys. sci. 2018 61A(1) 19-27

\title{
Structural, Electrical and Thermal Properties of Lead Borate Glass Doped by $\mathrm{V}_{2} \mathrm{O}_{5}$ Content
}

\author{
Rahma Hamed Marhoom ${ }^{\text {a }}$, Mohamed Said Dawelbeit ${ }^{\mathrm{a}}$, Essam Elsayed Assem ${ }^{\mathrm{bc} *}$ \\ and Adel Ashour Mohamed ${ }^{\text {bd }}$
}

${ }^{a}$ Department of Electronics Engineering, Faculty of Engineering and Technology, University of Gezira, Sudan

${ }^{b}$ Physics Department, Faculty of Science, Islamic University, Kingdom of Saudi Arabia

'Physics Department, Faculty of Science, Kafrelsheikh University, Egypt

'Physics Department, Faculty of Science, Minia University, Egypt

(received March 13, 2017; revised November 11, 2017; accepted February 6, 2018)

\begin{abstract}
Glass samples of compositions $\mathrm{xV}_{2} \mathrm{O}_{5}+\mathrm{y} \mathrm{Pb}+[100-(\mathrm{x}+\mathrm{y})] \mathrm{B}_{2} \mathrm{O}_{3}$ with the number of moles $\mathrm{x}$ varying from 0 to $2.5 \%$ and y varying from 0.2 to $0.195 \%$ are prepared by the technique of melting and quenching. The structural analysis of glass is achieved by studying the density and the molar volume. The glass density is increased from 1.8748 to $1.9347 \mathrm{~g} / \mathrm{cm}$ according to the increase of the vanadium pentoxide contents. Also, the structural analysis of these glasses points out the conversion of structural units of $\mathrm{BO}_{3}$ into $\mathrm{BO}_{4}$, which leads to increased density and molar volume. However, the transition temperature, the crystallization temperature, and the glass stability are decreased. The $\mathrm{VO}_{4}$ and $\mathrm{VO}_{5}$ structural units of vanadium are formed in the structural network. The electronic conduction of borate glass can be explained using Polaron hopping between $\mathrm{V}^{+4}$ and $\mathrm{V}^{+5}$. On the other hand, ionic conduction takes place by the $\mathrm{Pb}$ ion movement in all of the studied samples.
\end{abstract}

Keywords: glasses, density, molar volume, thermal properties, conductivity

\section{Introduction}

The shielding behavior of gamma radiation, optical properties of lead borate containing vanadium and structural properties of vanadium lead glasses show that vanadium plays a rule of a modifier (Rada et al., 2015; Abdelghany et al., 2012; Ghoneim et al., 2011). The effect of transition element on AC conductivity of borate glasses, vanadium borate glasses as rechargeable ionic batteries, elastic and structural properties of alkali borosilicate glasses containing vanadium, the structure and some physical properties of both borophosphate and borosilicate glasses containing vanadium have been studied (Ibrahim et al., 2017; Choi and Ryu, 2015; Laopaiboon and Bootjomchai, 2015; Afyon et al., 2014; Petru, 2010; Kashif et al., 2009; Marzouk et al., 2006; Assem, 2005; Khattak et al., 2003). Thermal properties of manganese bismo-borate glasses containing vanadium and semiconducting behavior of vanadium borate glasses have also been studied (Dahiya et al., 2016; Yousef et al., 2010). This paper details the preparation of a certain borate glass and highlights some of its structural, electrical and thermal properties using different experimental techniques. Six samples of borate glass were

*Author for correspondence;

E-mail: e_assem_2000@sci.kfs.edu.eg prepared and their densities were measured as a function of composition. The molar volume was then calculated from the density measurement results. Moreover, a thermal analyzer has been used to assess the thermal parameters such as glass transition temperature and crystallization temperature. Consequently, the stability of glasses and their network structure have been determined (Vijayalakshmi and Vasantharani, 2011).

The electrical conductivity of the glass system has been measured in the temperature range from 300 to $600 \mathrm{~K}$. The results show a semiconducting behavior, which is in agreement with earlier studies (Ashwajeet et al., 2016; Bhavani et al., 2013; Mansour et al., 2001). The semiconducting behavior might be attributed to the presence of more hopping centers like $\mathrm{V}^{+4}$ ions and $\mathrm{V}^{+5}$ ions in the glass network. The vanadium ions may also exist in the glass network in the unstable ionic state $\mathrm{V}^{+2}$ and $\mathrm{V}^{+3}$, which may also play a rule of hopping centers (Bhavani et al., 2013; Costigan et al., 2001; Chambers and Holliday, 1975). Furthermore, it is also important to mention that the study of electrical conductivity of this glass system shows an ionic conduction type produced by $\mathrm{Pb}$ ions and $\mathrm{B}^{+3}$ ions at a specific concentration of $\mathrm{V}_{2} \mathrm{O}_{5}$. Additionally, this kind of borate glass has the ability to accept vanadium ions in the network both as 
a former or modifier (Pranesh et al., 2015). The aim of this work is to study the effect of $\mathrm{V}_{2} \mathrm{O}_{5}$ and $\mathrm{Pb}$ doping on the thermal, electrical and structural properties of borate glass. This work is part of a more general project to investigate the thermal, electrical, structural, dielectric constant and forier transformer infrared (FTIR) of latter borate glass system. To our knowledge such an investigation has not been presented in literature.

\section{Materials and Methods}

Samples preparations. The composition of each glass sample is prepared according to the percentage formula:

[100- $(x+y)]$ moles of $\mathrm{B}_{2} \mathrm{O}_{3}+x$ moles of $\mathrm{V}_{2} \mathrm{O}_{5}+\mathrm{y}$ moles of $\mathrm{Pb}$

where:

$\mathrm{x}=0.0,0.5,1.0,1.5,2.0$, and 2.5 mole $\%, y=0.2$, $0.199,0.198,0.197,0.196$ and 0.195 mole $\%$ for the samples numbered 1, 2, 3, 4, 5 and 6 , respectively.

Boron trioxide is introduced in terms of crystalline boric acid $\left(\mathrm{H}_{3} \mathrm{BO}_{3}\right)$ in powder form with chemical purity grade $99.117 \%$ and containing impurities of sulphate $\left(\mathrm{SO}_{4}\right)$ (not more than $0.04 \%$ ) and water $\left(\mathrm{H}_{2} \mathrm{O}\right)$ (not more than $0.458 \%)$. While, vanadium pentoxide $\left(\mathrm{V}_{2} \mathrm{O}_{5}\right)$ is added with chemical purity grade $99.5 \%$ as oxide containing $0.5 \%$ of other vanadium oxides.

For each of the above-mentioned samples, a homogeneous mixture of boron trioxide and vanadium pentoxide are made by putting the mixture in a vessel which is moderately shaking horizontally and vertically. Afterward, each mixture is poured in a porcelain crucible and melted in an electrically heated furnace at $800{ }^{\circ} \mathrm{C}$ for two hours and then quenched in air.

Measurements. Density measurement. The glass density is measured using the standard Archimedes method with ethanol (of density $=0.78 \mathrm{~g} / \mathrm{cm}^{3}$ ) as the immersion liquid (Fig. 1). The masses, in this method, are measured by using a sensitive balance of range $0.0001-160.0000 \mathrm{~g}$. The density of each sample is calculated from the formula (Khasa et al., 2013):

$$
D_{G}=\left(D_{L} M_{G}\right) / \Delta M
$$

where:

$D_{G}$ and $D_{L}$ are the glass and liquid densities, respectively. $\mathrm{M}_{\mathrm{G}}$ is the mass of the sample in air and $\Delta \mathrm{M}$ is the equivalent loss of the mass in the liquid.
Molar volume calculations. The molar volume, $\mathrm{V}_{\mathrm{m}}$, for each sample is calculated from the formula (Khasa et al., 2012):

$$
\mathrm{V}_{\mathrm{m}}=\sum \text { ni } \mathrm{M}_{\mathrm{i}} / \mathrm{D}_{\mathrm{G}}
$$

where:

$\mathrm{M}_{\mathrm{i}}$ is the molar mass of the component which enters with the ratio $\mathrm{n}_{\mathrm{i}}$.

Electrical conductivity. The resistance, R, of each sample at different temperatures in the range 310-600 $\mathrm{K}$ is measured as follows: the sample is held by a copper holder and is heated up to $600 \mathrm{~K}$ by an electrical furnace. The heating is then stopped and the sample is left to cool freely down to $310 \mathrm{~K}$.

The resistance of the sample is measured in the abovementioned range of temperature in steps of $10 \mathrm{~K}$ decreasingly, using a digital multimeter (DT9205A+) ranged from $200 \Omega-20 \mathrm{M} \Omega$. From the results of the resistance measurements, the electrical conductivity is calculated for each sample in the desired temperature range. A plot for each sample, Fig. 2, is made for the natural logarithm of the conductivity, $\operatorname{Ln}(\sigma)$, versus the reciprocal of the absolute temperature (1/T). From the plots the activation energy, $E_{a}$ of the electrical conductivity is calculated as a function of temperature using Arrhenius relation (Atkins and Julio, 2010; Wallwork et al., 1977; James and Prichard, 1974):

$$
\sigma=\sigma_{\circ} \exp \left(-\mathrm{E}_{\mathrm{a}} / \mathrm{k}_{\mathrm{B}} \mathrm{T}\right)
$$

where:

$\sigma_{\circ}$ is a constant and $k_{B}$ is the Boltzmann's constant. Fig. 3 gives the activation energy of the electrical conductivity of the studied glass as a function of composition.

Differential scanning calorimetry. The differential scanning calorimetry (DSC) of the studied samples has been performed using the TA instrument (Inc.159 Lukens, New Castle, DE19720) programmed heating rates $10 \mathrm{~K} / \mathrm{min}, 20 \mathrm{~K} / \mathrm{min}, 30 \mathrm{~K} / \mathrm{min}, 40 \mathrm{~K} / \mathrm{min}$ at 300 $1000 \mathrm{~K}$ temperature range. The glass crystallization temperature , $T_{c}$, of these glasses has been determined from differential scanning calorimetry thermograms (Fig. 5 with sample 2 as a selected sample). The crystallization temperature at different heating rates $(\alpha)$ have been plotted as a function of vanadium pentoxide $\left(\mathrm{V}_{2} \mathrm{O}_{5}\right)$ concentration (Fig. 6). Finally, as can be seen in Fig. 7, the activation energy of the crystallization 
temperature is deduced using Kissinger's equation (Faeghinia et al., 2016; Yadav et al., 2012):

$$
\operatorname{Ln}\left(\alpha / \mathrm{T}_{\mathrm{c}}^{2}\right)=-\left(\mathrm{E}_{\mathrm{c}} / \mathrm{RT}_{\mathrm{c}}\right)+\mathrm{constant}
$$

where:

$\alpha$ is the heating rate and $\mathrm{R}$ is the universal gas constant. It is seen from equation (5) that the plot of $\mathrm{Ln}\left(\alpha / \mathrm{T}_{\mathrm{c}}{ }^{2}\right)$ versus $1 / T_{c}$ is a straight line, from which the activation energy of crystallization temperature, $\mathrm{E}_{\mathrm{c}}$, is calculated. A plot of activation energy of crystallization as a function of $\mathrm{V}_{2} \mathrm{O}_{5}$ concentration is then made.

\section{Results and Discussion}

Density and molar volume. The density measurement is an important tool to detect the structural changes in the glass network (Soliman, 2008; Mansour et al., 2001). The density is supposed to change when the structure of the glass changes (Singh et al., 2011) while the molar volume changes according to the oxygen spatial distribution (Ashwajeet et al., 2016).

It can be seen from the Fig. 1, that the density of glass increases from 1.8748 to $1.9347 \mathrm{~g} / \mathrm{cm}^{3}$ with increasing vanadium pentoxide content from 0 mole $\%$ to 2.5 mole $\%$. The increase of density may be attributed to: (Kashif et al., 2010; Doweidar et al., 2005):

(i) Replacement of low density ions of boron (2.46 $\left.\mathrm{g} / \mathrm{cm}^{3}\right)$ by higher density ions of vanadium density $\left(6.11 \mathrm{~g} / \mathrm{cm}^{3}\right)$.

(ii) Structural changes that cause conversion of $\mathrm{BO}_{3}$ to $\mathrm{BO}_{4}$.

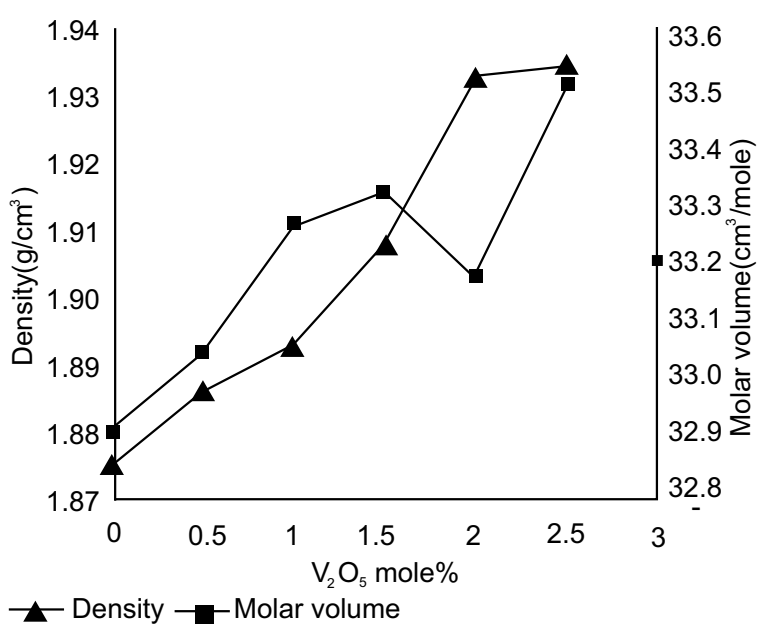

Fig. 1. Effect of doping $\mathrm{V}_{2} \mathrm{O}_{5}$ on density and molar volume of borate glass.
Regarding the second reason, the $\mathrm{BO}_{4}$ is a denser structural unit than any $\mathrm{BO}_{3}$ species (Singh et al., 2011; Assem and Elmehasseb, 2011; Gohar et al., 1993). The random configuration of the $\mathrm{B}_{2} \mathrm{O}_{3}$ glass network is relatively open; it contains large voids filled by $\mathrm{V}_{2} \mathrm{O}_{5}$ content. Hence, the mass increases while the volume expands slightly, and this causes the density to increase. The molar volume also increases as shown in Fig. 1. The gradual change appeared in the molar volume can be explained as follows: the excess of nonbridging oxygen atoms supplied to the glass structure by the addition of the $\mathrm{V}_{2} \mathrm{O}_{5}$ contents could be the cause of the conversion of triangular $\mathrm{BO}_{3}$ units into tetrahedral $\mathrm{BO}_{4}$ units, which led to an expansion in the glass network structure. Moreover, the increase of molar volume of the glass system is attributed to the modifier behavior of the doping oxides, which produces nonbridging oxygen and expands the lattice (Assem and Elmehasseb, 2011).

The changes in density and molar volume indicate that $\mathrm{V}_{2} \mathrm{O}_{5}$ acts as a glass modifier. The vanadium pentoxide introduced in the glass network exist in the form of two ions, $\mathrm{V}^{5+}$ (which acts as a glass former) and $\mathrm{V}^{4+}$ (which acts as a glass modifier), by occupying the empty spaces in the formerly open glass network. In our glass system, it seems that the modifier behavior is predominant, so that the glass network is disrupted and expanded, which in turn increases the molar volume (Gautam et al., 2012; Assem and Elmehasseb, 2011; Kashif et al., 2010).

Electrical conductivity. The electrical conductivity of glasses varies with composition and rises with increasing temperature. Studies of the electrical conduction mechanism in several glass systems showed that the thermal activation energy plays a dominant role in electrical conduction (Panchal, 2014; Dhote, 2014). It was also observed, by the latter authors, that the activation energy is influenced by the changes of the molar ratio of glass modifiers. The conductivity of glasses might be electronic, ionic or a mixture of both. The mobility of ions depends on both glass temperature and composition (Gawande et al., 2015; Meikhail, 2005). At high temperatures, most semiconductors tend to show rising movement of ions (Vijayalakshmi and Vasantharani, 2011; Kanchan and Panchal, 1998).

The glasses with a basic structure composed of $\mathrm{B}_{2} \mathrm{O}_{3}$ are insulating in nature and insensitive to the ionic migration, due to the high total energy required to produce $\mathrm{B}^{3+}$ ions, which is far more than would be 
compensated by the lattice energies of ionic compounds or by hydration of such ions in solution. However, the addition of transition metal ions and alkaline earth ions to these glasses can produce mixed types of electrical conductivity (electronic and ionic) and thereby their electrical properties would be improved (Kundu et al., 2010; Kanchan and Panchal, 1998; Ahmed et al., 1984).

Figure 2 shows the temperature dependence of the conductivity of the studied glass samples. It has been observed that the conductivity of all samples increases as the temperature increases. The ionic conduction takes place by the mobility of $\mathrm{Pb}$ ions in all samples. In samples with vanadium content the electronic conduction increased due to the increase of the conversion of $\mathrm{V}^{4+}$ ions into $\mathrm{V}^{5+}$ ions as the vanadium pentoxide content is increased. As seen from molar volume results, the presence of nonbridging oxygen causes expansion in the glass structure, which facilitates the mobility of the lead ions and increases the ionic conductivity. The vanadium pentoxide ions contribute gradually to (electronic) conduction according to their amount in the samples. The increase in $\mathrm{V}_{2} \mathrm{O}_{5}$ content increases the electronic hopping between $\mathrm{V}^{4+}$ ions and $\mathrm{V}^{5+}$ ions (Khasa et al., 2014; Bhavani et al., 2013; Maloney, 1968). It has been observed that although samples 3 and 4 has less vanadium content than samples 5 and 6 the increase in their conductivity is higher. The reason for this is the appearance of ionic conduction carried by $\mathrm{B}^{3+}$ and $\mathrm{Pb}$ ions. However, the $\mathrm{B}^{3+}$ and $\mathrm{Pb}$ ionic conduction is less in samples 5 and 6 compared to samples 3 and 4 because the introduction of $\mathrm{V}_{2} \mathrm{O}_{5}$ into the glass network causes the conversion of $\mathrm{BO}_{3}$ units into $\mathrm{BO}_{4}$ units. Thus addition

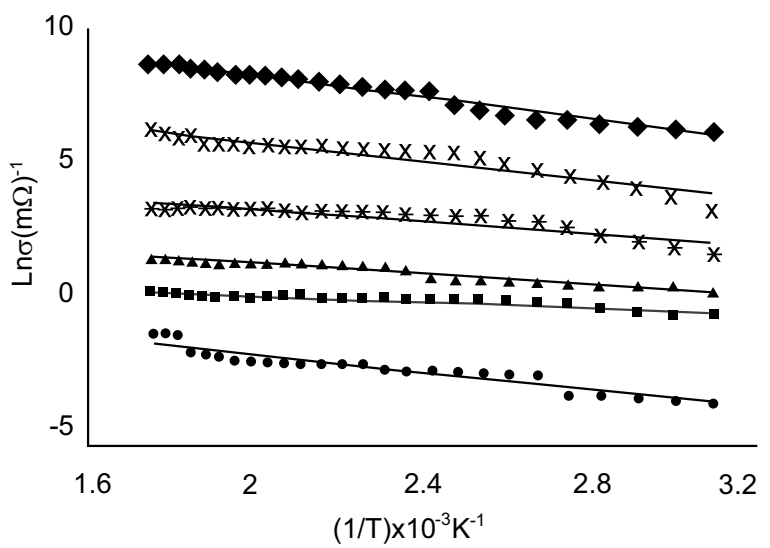

* Sample $1 \bullet$ Sample 2 x Sample $3 \bullet$ Sample 4

^Sample 5 - Sample 6

Fig. 2. Temperature dependence of electrical conductivity. of more $\mathrm{V}_{2} \mathrm{O}_{5}$ produces a larger amount of nonbridging oxygen. The increase in the nonbridging oxygen ions, in samples 5 and 6, may cause blocking to the movement of the $\mathrm{B}^{3+}$ and $\mathrm{Pb}$ ions, as compared to samples 3 and 4. This blocking decreases the $\mathrm{B}^{+3}$ and $\mathrm{Pb}$ ionic conduction as can be seen in Fig. 2 (Pranesh et al., 2015; Nagaraja et al., 2014; Mansour et al., 2001). Another reason is that an increase in the nonbridging oxygen ions increases the distance between vanadium ions, this decreases the electron hopping between $\mathrm{V}^{5+}$ and $\mathrm{V}^{4+}$ which, in turn, decreases the conductivity (Al-Hajry et al., 2005).

The variations of both electrical conductivity and its activation energy with the composition at constant temperature are shown in Fig. 3-4, respectively, Fig. 4 shows that a long side the increase of the vanadium pentoxide content the conductivity is also slightly increased. This is in agreement with previous studies

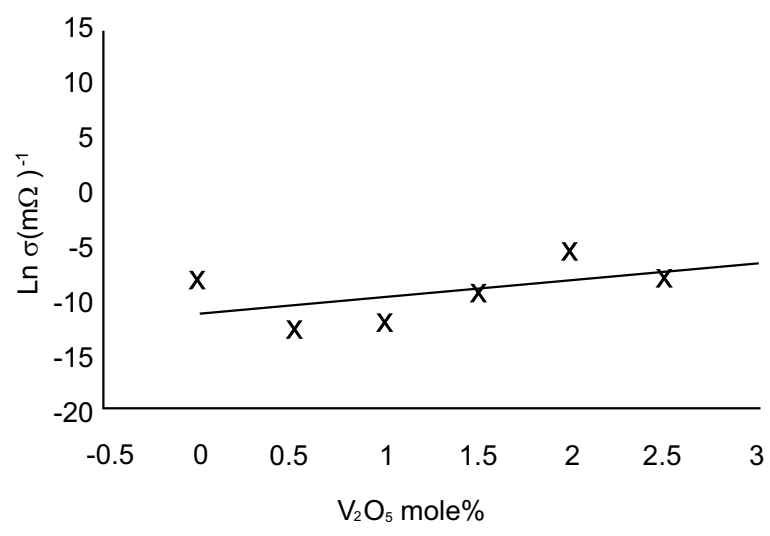

Fig. 3. Composition dependence of electrical conductivity at $313 \mathrm{~K}$.

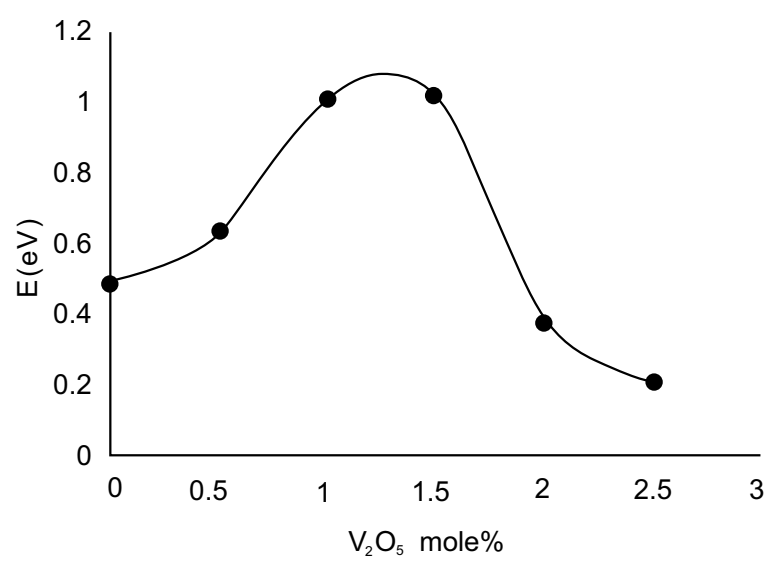

Fig. 4. Activation energy (E) for different $\mathrm{V}_{2} \mathrm{O}_{5}$ concentrations. 
(Bhavani et al., 2013; Mansour et al., 2001; Shimakawa and Miyake, 1989).

Differential scanning calorimetry. The thermogram of the Fig. 5 represents a differential scanning calorimetry for the selected representative sample (sample 2) at four different heating rates. It can be seen that all of the samples have similar differential thermal calorimetry behavior. The curves show deep broaden endothermic peaks in the range 442 - $472 \mathrm{~K}$ due to water dehydration because these glasses are unstable against atmospheric moisture (Bhavani et al., 2013; Fatih et al., 2006). They show a broad halo, which is a characteristic of amorphous nature of the system and an absence of crystalline phase (Grega et al., 2010). All the thermograms show that there are no clear sharp peaks representing the characteristic temperature, such as glass transition temperature and crystallization temperature as well as absence of melting temperatures. Thus the thermograms indicate high resistance to crystallization (Thombre, 2016).

Figure 5 shows the increasing of transition temperature with increasing heating rate. This indicates the lack of tendency to crystallization of the investigated glass system (Assem et al., 2006). The transition temperatures of the studied samples become relatively low as the concentration of $\mathrm{V}_{2} \mathrm{O}_{5}$ is increased compared to other glasses not containing $\mathrm{V}_{2} \mathrm{O}_{5}$. This might be attributed to the replacement of strong B-O bonds by weak V-O bonds (Dahiya et al., 2015; Pranesh et al., 2015; Kashif et al., 2010).

Figures 6-7 show a decrease in both transition temperature, $\mathrm{T}_{\mathrm{g}}$ and crystallization temperature, $\mathrm{T}_{\mathrm{c}}$ with increasing $\mathrm{V}_{2} \mathrm{O}_{5}$ content at a fixed heating rate. Both $\mathrm{T}_{\mathrm{g}}$ and

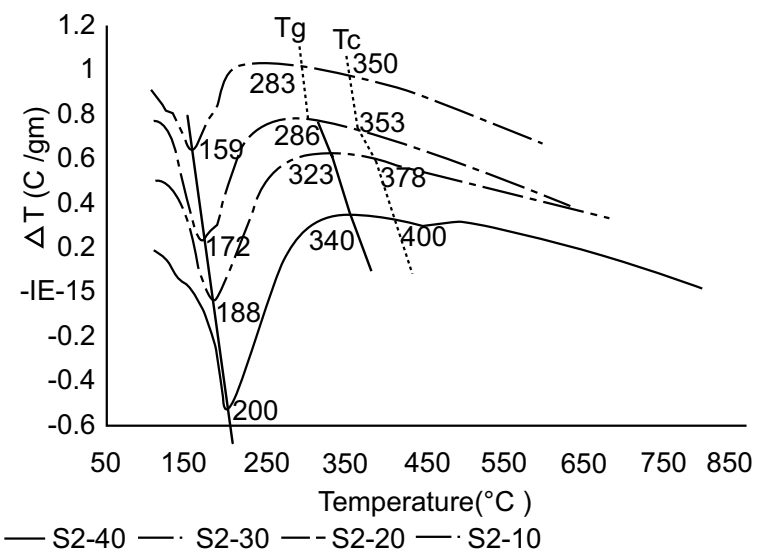

Fig. 5. DSC pattern of sample 2 at different heating rates $(10-40) \mathrm{K} / \mathrm{min}$.
$T_{c}$ depend on the nonbridging oxygen density of the glass network, which is a measure of the tightness of packing factor. The oxygen density of the glass structure increases according to the degree of the replacement of $\mathrm{B}_{2} \mathrm{O}_{3}$ by $\mathrm{V}_{2} \mathrm{O}_{5}$ (Dahiya et al., 2015; Silva et al., 2014). Another reason for the decrease of the two temperatures $\mathrm{T}_{\mathrm{g}}$ and $\mathrm{T}_{\mathrm{c}}$ is due to the replacement of the weaker O-V$\mathrm{O}$ bonds by stronger B-O-B and B-O-V bonds. The boron atoms, which have small radii and strong field's strength, are replaced by the vanadium atoms, which have large radii and small field's strength. These two reasons lead to a decrease in the packing and the two temperatures $\mathrm{T}_{\mathrm{g}}$ and $\mathrm{T}_{\mathrm{c}}$ (Al-Hajry et al., 2005; Mansour et al., 2001).

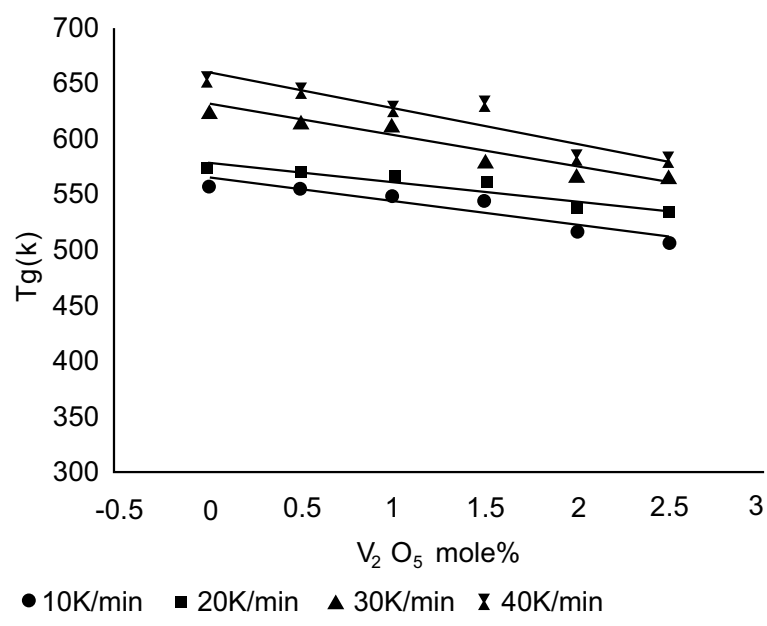

Fig. 6. Variation of glass transition temperature, $\mathrm{T}_{\mathrm{g}}$, with composition.

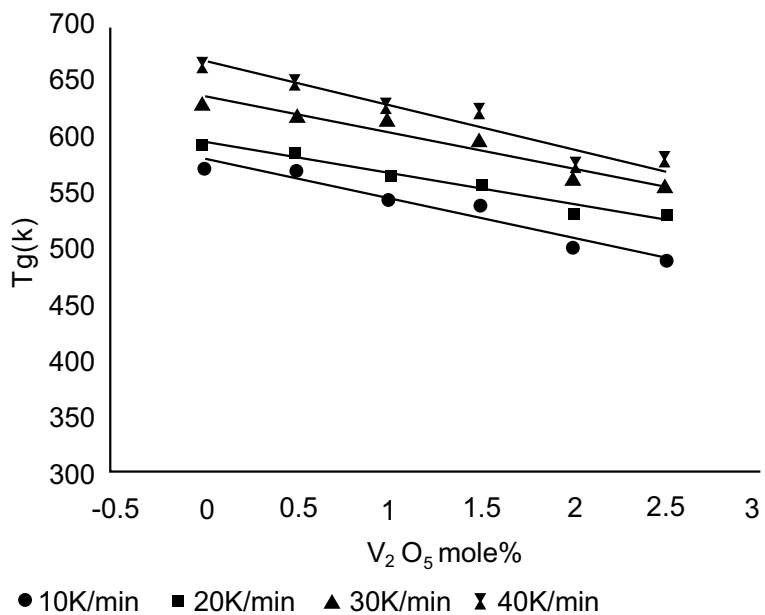

Fig. 7. Variation of crystallization temperature, $\mathrm{T}_{\mathrm{c}}$, with composition. 
Figure 8 shows a decrease in the degree of the glass stability with increasing concentration of $\mathrm{V}_{2} \mathrm{O}_{5}$, although it is still large as compared to other glass systems. This is due to the increase in nonbridging oxygen and molar volume (Asha, 2014; Thombre and Thombre, 2014; Desirena et al., 2009). The decrease of the glass transition temperature and the high stability of the glass system with increasing concentration of $\mathrm{V}_{2} \mathrm{O}_{5}$ makes this glass system useful for low $\mathrm{T}_{\mathrm{g}}$ applications (Khasa et al., 2014; Khan et al., 2014).

From Fig. 9, it can be seen that the activation energy of the crystallization is constant with increasing $\mathrm{V}_{2} \mathrm{O}_{5}$ concentration. This is due to the resistance of crystallization of the glass system.

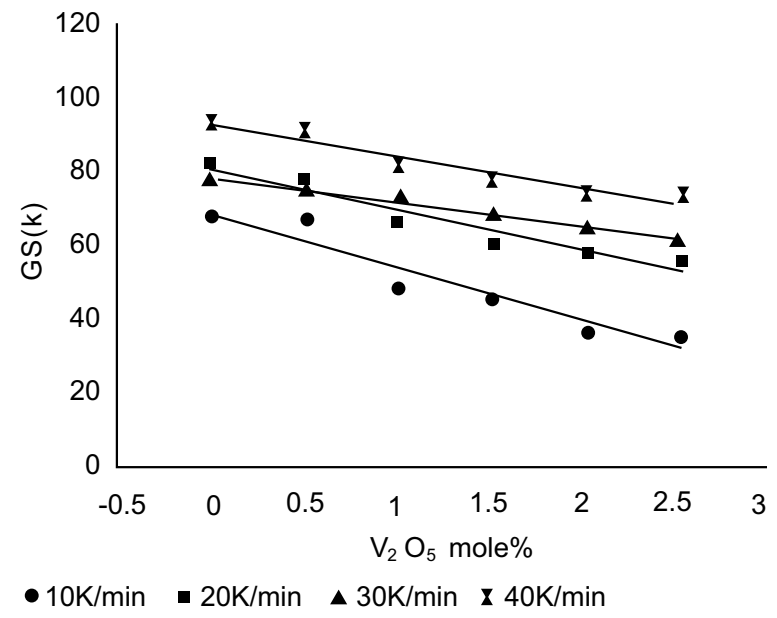

Fig. 8. Variation of glass stability (GS) with composition.

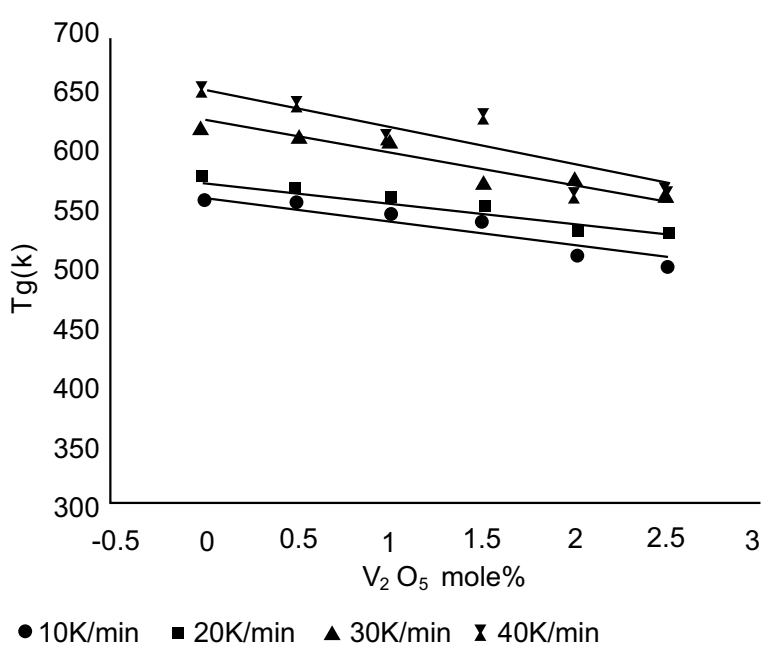

Fig. 9. Composition dependence of the activation energy of crystallization.

\section{Conclusion}

The density of the borate glass with vanadium content increases with the replacement of $\mathrm{B}_{2} \mathrm{O}_{3}$ with $\mathrm{V}_{2} \mathrm{O}_{5}$ and $\mathrm{Pb}$, due to the fact that they have higher molar mass. The molar volume increases with increasing $\mathrm{V}_{2} \mathrm{O}_{5}$ and $\mathrm{Pb}$ due to increasing nonbridging oxygen and expanding of lattice.

The electrical conduction of the above mentioned glass system is partly ionic and partly electronic. The ionic conduction reaches its maximum value at 1.5 mole $\%$ of $\mathrm{V}_{2} \mathrm{O}_{5}$ and 0.197 mole $\%$ of $\mathrm{Pb}$ concentration above which it decreases due to blocking effect. The thermal parameters decrease with increasing $\mathrm{V}_{2} \mathrm{O}_{5}$ content and decreasing $\mathrm{Pb}$ content, due to the nonbridging oxygen density of the glass network. The activation energy of crystallization is constant with respect to doped vanadium oxide. This behavior may be attributed to the high resistance of crystallization of this glass system.

\section{References}

Abdelghany, A.M., ElBatal, H.A., Marei, L.K. 2012. Optical and shielding behavior studies of vanadiumdoped lead borate glasses. Radiation Effects and Defects in Solids, 167: 49-58.

Afyon, S., Krumeich, F., Mensing, C., Borgschulte, A., Nesper, R. 2014. New high capacity cathode materials for rechargeable $\mathrm{Li}$-ion batteries: vanadateborate glasses. Scientific Reports, 4: doi10:1038/srep 07113.

Ahmed, M.M., Hogarth, C.A., Ghaghara, M.A. 1984. $\mathrm{X}$-ray diffraction, density and electrical conductivity studies of some zinc borate glasses. Journal of Material Science Letters, 3: 341-344.

Al-Hajry, A., Soliman, A.A., El-Desoky, M.M. 2005. Electrical and thermal properties of semiconducting $\mathrm{Fe}_{2} \mathrm{O}_{5}-\mathrm{Bi}_{2} \mathrm{O}_{5}-\mathrm{Na}_{2} \mathrm{~B}_{4} \mathrm{O}_{7}$ glasses. Thermochimica ActaElsevier, 427: 181-186.

Asha, R. 2014. Physical, Thermal, Transport and Optical Studies on Borate and Phosphate Glasses Synthesized by Microwave Method. Ph.D. Thesis. Jain University, Bangalore, India.

Ashwajeet, J.S., Sankarappa, T., Rammana, R., Sujatha, T. 2016. Study of polaron transport mechanisms in two transition metal ions doped borophosphate glasses. Glass Physics and Chemistry, 42: 27-32.

Assem, E.E., Elmehasseb, I. 2011. Structure, magnetic and electrical studies on vanadium phosphate glasses containing different oxides. Journal Material 
Science, 46: 2071-2073.

Assem, E.E., Mahmoud, K.R., Sharshar, T., Siligardi, C.J. 2006. Structure, magnetic and positron lifetime studies on $\mathrm{CaO}-\mathrm{ZrO}_{2}-\mathrm{SiO}_{2}$ glass system doped with vanadium oxides. Journal of Physics D: Applied Physics, 39: 734-739.

Assem, E.E. 2005. Effect of iron oxide on the structure, electrical and magnetic properties of $(70 \%$ mole $\mathrm{V}_{2} \mathrm{O}_{5^{-}}(15-\mathrm{x}) \%$ mole $\mathrm{P}_{2} \mathrm{O}_{5^{-}}-15 \%$ mole $\left.\mathrm{B}_{2} \mathrm{O}_{3}\right)$ semi conducting glass system. Key Engineering Materials, 280: 327-332.

Atkins, P., Julio, De P. 2010. Physical Chemistry $9^{\text {th }}$ edition, pp. 835-859, Oxford University Press, New Delhi, India.

Bhavani, P., Nagalakshmi, V., Iqbal, A.W., Emmanuel, K.L. 2013. Structrural study of $\mathrm{PbO}-\mathrm{PbF}_{2}-\mathrm{B}_{2} \mathrm{O}_{3}$ glass system doped with $\mathrm{V}_{2} \mathrm{O}_{5}$ through spectroscopic and magnetic properties. Chemistry Journal, 3: 75-80.

Chambers, C., Holliday, A.K. 1975. Modern Inorganic Chemistry, pp. 359-369, $1^{\text {st }}$ edition, Butterworth \& Co., UK.

Choi, Su-Y., Ryu, B.K. 2015. Nanocrystallization of vanadium borophosphate glass for improving the electrical and catalytic properties. Journal of Nanomaterials, doi.org/10.1155/2015/201597.

Costigan, M., Gary, R., Dopson, S. 2001. Vanadium pentoxide and other inorganic vanadium compounds. Concise International Chemical Assessment Document 29, UK.

Dahiya, M.S., Khasa, S., Agarwal, A. 2016. Thermal characterization of novel magnesium oxyhalide bismo-borate glass doped with $\mathrm{VO}_{2}+$ ions. Journal of Thermal Analysis and Calorimetry, 123: 457465.

Dahiya, M.S., Khasa, S., Agarwal, A. 2015. Physical thermal, structural and optical absorption study of vanadyl doped magnesium ox-chloride bismoborate glasses. Journal of Asian Ceramic Societies, 3: 206-211.

Desirena, H., Schulzgen, A., Sabet, S., Ramos-Ortiz, G., De la Rosa, E., Peyghambarian, N. 2009. Effect of alkali metal oxides $\mathrm{R}_{2} \mathrm{O}(\mathrm{R}=\mathrm{Li}, \mathrm{Na}, \mathrm{K}, \mathrm{Rb}$, and $\mathrm{Cs})$ and network intermediate $\mathrm{MO}(\mathrm{M}=\mathrm{Zn}, \mathrm{Mg}, \mathrm{Ba}$ and $\mathrm{Pb}$ in tellurite glasses. Optical Materials, 31: 784-789.

Dhote, D.S. 2014. Transport properties of vanadium borate glasses. International Research Journal of Science and Engineering, 2: 161-166.
Doweidar, H., Eldamroui, G.M., Moustafa, Y., Ramadan, R.M. 2005. Density of mixed alkali borate glasses: A structural analysis. Physica B: Physics of Condensed Matter, 362: 123-132.

Faeghinia, A., Nemati, R., Sheighani, M. 2016. The crystallization kinetic of Te-Li glass. Journal of Material, Mechanics, and Manufacturing, 5: 24-27.

Fatih, S., Fatih, D., Murat, B., Hüseyin, O. 2006. Kinetic analysis of (thermal) transition decomposition of boric acid thermogravimetric data. Korean Journal of Chemical Engineering, 23: 736-740.

Gautam, C., Yadav, A.K., Singh, A.K. 2012. A review on infra-red spectroscopy of borate glasses with effect of different additives. International Scholarly Research Network (ISRN) Ceramics, 2012: 1-17.

Gawande, W.J., Yawale, S.S., Yawale, S.P. 2015. Hopping conduction mechanism in amorphous $\mathrm{CuO}-\mathrm{Bi}_{2} \mathrm{O}_{3}$ semiconducting pellets. International Journal of Innovative Science, Engineering and Technology, 2: 209-213.

Ghoneim, N.A., ElBatal, H.A., Abdelghany, A.M., Ali, I.S. 2011. Shielding behavior of $\mathrm{V}_{2} \mathrm{O}_{5}$ doped lead borate glasses towards gamma irradiation. Journal of Alloys and Compounds, 509: 69136919.

Gohar, I.A., Megahed, A.A., Assem, E.E. 1993. Halogen form in the calcium borate glasses containing iron. Journal of Crystal Research Technology, 28: 217-224.

Grega, K., Jozef, M., Permoz, M. 2010. Differential thermal analysis and differential scanning calorimetry as a method of material investigation. Material and Geoenvironmental, 1: 127-142.

Ibrahim, S., Marzouk, M.A., El-Komy, G.M. 2017. Structural characteristics and electrical conductivity of vanadium-doped lithium ultraphosphate glasses. Silicon, 9: 403-410.

James, A.M., Prichard, F.E. 1974. Practical Physical Chemistry, $3^{\text {rd }}$ edition, Prentice Hall Press, ISBN 978-0582442597.

Kanchan, D.K., Panchal, H.R. 1998. Infrared absorption study of potassium -boro-vanadate-iron glasses. Turkish Journal of Physics, 22: 989-996.

Kashif, I., Abd-Elghany, A., Abd-Elmaboud, A., Elshirbeny, M.A., Sanad, A.M. 2010. IR, density, and DTA studies the effect of replacing $\mathrm{Pb}_{3} \mathrm{O}_{4}$ by $\mathrm{CuO}$ in Pseudo-binary $\mathrm{Li}_{2} \mathrm{~B}_{4} \mathrm{O}_{7}-\mathrm{Pb}_{3} \mathrm{O}_{4}$ glass 
system. Journal of Alloys and Compound, 503: 384-388.

Kashif, I., Rahman, S.A., Soliman, A.A., Ibrahim, E.M., Abdel-Khalek, E.K., Mostafa, A.G., Sanad, A.M., Physica, B. 2009. Effect of alkali content on AC conductivity of borate glasses containing two transition metals. Physica B: Physics of Condensed Matter, 404: 3842-3849.

Khan, M.S., Shahzadi, P., Alam, S., Javed, K., Shaheen, F., Naqvi, J., Shahnaz, A. 2014. Developement of heat resistant of borosilicate glass doped with sodium silico fluoride compound. Journal of Chemistry and Materials Research, 4: 13-18.

Khasa, S., Dahiya, S., Agarwal, A. 2014. Effect of alkali edition on DC conductivity \& thermal properties of vanadium-bismo- borate glasses. AIP Conference Proceedings, 1591: 796-798.

Khasa, S., Dahiya, M.S., Agarwal, A. 2013. Structural investigations of some lithium vanadoxide bismoborate glasses. Journal of Integrated Science and Technology, 1: 44-47.

Khasa, S., Manjeet, A.A. 2012. Synthesis and characterization of vanadyl ion doped alkaline halide borate glasses. International Journal of Physics \& Mathematical Science, 2: 104-108.

Khattak, G.D., Tabet, N., Salim, M.A. 2003. X-ray photoelectron spectroscopic studies of vanadiumstrontium-borate $\left[\left(\mathrm{V}_{2} \mathrm{O}_{5}\right) \times(\mathrm{SrO}) 0.2\left(\mathrm{~B}_{2} \mathrm{O}_{3}\right)\right.$ 0.8$\mathrm{x}$ ]oxide glasses. Journal of Electron Spectroscopy and Related Phenomena, 133: 103-111.

Kundu, V., Dhiman, R.L., Maan, A.S., Goyal, D.R., Arora, S. 2010. Characterization and electrical conductivity of vanadium doped strontium bismuth borate glasses. Journal of Optoelectronics and Advanced Materials, 12: 2373-2379.

Laopaiboon, R., Bootjomchai, C. 2015. Characterization of elastic and structural properties of alkaliborosilicate glasses doped with vanadium oxide. Glass Physics and Chemistry, 41: 352-358.

Maloney, F.J.T. 1968. Glass in the Modern World: A study in Materials Development, Published by Aldus Books Ltd., ISBN 10:0490001068.

Mansour, E., Eldamrawi, G.M., Moustafa, Y.M., AbdElmaksoud, S., Doweidar, H. 2001. Polaronic conduction in barium borate glasses containing iron oxide. Physica B, 293: 268-275.

Marzouk, S.Y., Elalaily, N.A., Ezz-Eldin, F.M., W.M. 2006. Optical absorption of gamma-irradiated lithium-borate glasses doped with different transition metal oxides, Physica B: Condensed Matter, 382: 340-351.

Meikhail, M.S. 2005. Conduction modelling in mixed alkali borate glasses. Journal of Pure \& Applied Physics, 1: 191-197.

Nagaraja, N., Sankarappa, T., Sujatha, T.D.C. 2014. Dielectric relaxation studies in $\mathrm{CuO}$ doped borate glasses. International Journal of Engineering Science and Innovative Technology, 3: 284-289.

Panchal, H.R. 2014. Structural, physical and electrical properties of boro-vanadate-iron glasses doped with $\mathrm{K}_{2} \mathrm{O}$ alkali. Turkish Journal of Physics, 38: 136-144.

Petru, P. 2010. Structural investigations of some bismuth-borate-vanadate glasses doped with gadolinium ions. Journal of Materials Science: Materials in Electronics, 21: 338-342.

Pranesh, S., Krishna, D.K., Rumu, H., Ajithkumar T.G., Abraham, G., Mishra, R.K., Kaushik, C.P., Dey, G.K., Pinckney, L. 2015. Vanadium in borosilicate glass. Journal of the American Ceramic Society, 98: $88-96$.

Rada, M., Rus, L., Rada, S., Pascuta, P., Stan, S., Dura, N., Rusu, T., Culea, E. 2015. Role of vanadium ions on structural, optical and electrochemical properties of the vanadate-lead glasses. Journal of Non-Crystalline Solids, 414: 59-65.

Shimakawa, K., Miyake, K. 1989. Hopping transport of localized electron in amorphous carbon films. American Physics Society, 39: 7578-7584.

Silva, V.A., Nascimento, M.I.F., Morais, P.C., Datas, N.O. 2014. The structure role of Ti in a thermally -treated $\mathrm{Li}_{2} \mathrm{O}-\mathrm{B}_{2} \mathrm{O}_{3}-\mathrm{AL}_{2} \mathrm{O}_{3}$ glass system. Journal of Non-Crystalline Solids, 404: 104-108

Singh, G., Singh, P., Kaur, P., Kaur, S., Singh, D.P. 2011. Role of $\mathrm{V}_{2} \mathrm{O}_{5}$ in structural properties of $\mathrm{V}_{2} \mathrm{O}_{5^{-}}$ $\mathrm{MnO}_{2}-\mathrm{PbO}-\mathrm{B}_{2} \mathrm{O}_{3}$ Glasses. Materials Physics and Mechanics, 12: 58-63.

Soliman, A.A. 2008. Electrical and thermal properties of semiconducting $\mathrm{Fe}_{2} \mathrm{O}_{5}-\mathrm{Bi}_{2} \mathrm{O}_{5}-\mathrm{Na}_{2} \mathrm{~B}_{4} \mathrm{O}_{7}$ glasses. Armenian Journal of Physics, 1: 188-197.

Thombre, D.B. 2016. Estimation of glass-forming ability and glass stability of lithium-borosilicate glasses. International Journal of Innovative Research in Science, Engineering and Technology, 5: 124-132.

Thombre, D.B., Thombre, M.D. 2014. Study of physical properties of lithium borosilicate glasses. International Journal of Engineering Research and 
Development, 10: 9-19.

Vijayalakshmi, M., Vasantharani, P. 2011. Characterization of $(50-\mathrm{x}) \mathrm{Pb} . \mathrm{xiO}_{2}$ Glass system by spectroscopic and thermal analysis. International Journal of Recent Scientific Research, 2: 10-13.

Wallwork, S.C., Phil, M.A.D., Inst, P.F., Grant, D.J.W. 1977. Physical Chemistry for Student of Pharmacy and Biology, pp. 164-171, $3^{\text {rd }}$ edition, Longman, London and NewYork, USA.
Yadav, A.K., Gautam, C., Singh, P. 2012. Crystallization kinematic and dielectric behaviour of $(\mathrm{Ba}, \mathrm{Sr}) \mathrm{TiO}_{3}$ borosilicate glass ceramics. New Journal of Glass and Ceramics, 2: 126-131.

Yousef, El-Sayed, Shaaban, E.R., Hawary, M., AlSalami, A.E., Al-Assiri, M.S. 2010. Crystallization kinetics of semiconducting vanadium borate glass using DSC. Physica Scripta, doi.org/10.1088/00318949/82/04/045603. 